\title{
IS EDUCATION: THE CHANGING COMPLEXITY OF RELEVANCE
}

\author{
David W. Johnson, Utah Valley State College, johnsoda@uvsc.edu \\ Christopher G. Jones, Utah Valley State College, jonescg@uvsc.edu
}

\begin{abstract}
Because of the rapid pace of business and technological change, the relevance of an IS education has been challenged by students, practitioners, and academics. This paper explores the complex, multi-dimensional characteristics of relevance for an IS department. A relevance model and rubric are presented to help an IS department understand and measure the relevance of its programs within the context of its various stakeholders, products, and processes.
\end{abstract}

Keywords: IS Education, Relevance, Model, Complexity, Change, Rubric

\section{INTRODUCTION}

It has been said that the only thing constant in life is change. This is especially true in the business world as advances in technology have helped to "flatten" the earth [7] and have made globalization a key factor in many business decisions. Since information systems (IS) education resides at the boundary between technology and business, this double-dose of change has had a profound effect on IS programs and educators who must deal with the realities of a higher education system that seeks to preserve the traditions of the past and under which change is painstakingly slow.

This academic latency has caused some to question the role [6] and relevance [9] of IS education and research [4]. In fact, a recent article by Andriole [3] points out that, in spite of the efforts of academics to develop model curricula that respond to change, the gap between "theory" and "practice" is widening. His implication is that IS educators should become more focused on a "Quest for Relevance." While this gap is not new [12], the problem has become exacerbated by the fact that the .COM bomb of the stock market had become the .IS.EDU snafu of dwindling enrollments [10]. All of this has put IS department administrators under increasing pressure to demonstrate their program's relevance.

This paper addresses the question of relevance within an IS program. The following section discusses the attributes of relevance which make its attainment a complex process. Following this, a Relevance Model is presented indicating aspects of the real-world environment which influence the main factors, or dimensions, of relevance. Next, a Relevance Rubric is described, indicating a quantitative approach to the measurement of relevance using "Relevance Points." Finally, a simplified case example is presented to demonstrate the use of the model and the rubric.

\section{THE COMPLEXITY OF RELEVANCE}

Relevance is sometimes viewed as a dichotomous property of IS education taken as a whole. Westfall [13], for example, states that "many practitioners believe that IS research is not relevant." In a similar way, some IS departments claim relevance of their program based on the fact that their curriculum is based on general curriculum models created by academicians or on requirements needed to satisfy accrediting groups such as AACSB [1] or ABET [2]. Yet practitioner surveys often refute such claims [3]. Other surveys, such as Hoffman [8], suggest that relevance should have a discrete measure such as having a group of CIOs give IS undergraduate education a grade such as a "B-" or a "C+".

Such relevance ratings, however, typically ignore the fact that IS departments have their own specific stakeholders with additional interests beyond the curriculum. For such stakeholders, relevance is determined by the value associated with a specific context. Thus, overall relevance for an IS program involves doing the right things (from multiple perspectives) in the right way (with multiple auditors) under multiple constraints. This being said, it seems clear that an IS program cannot be everything to everyone. Rather its relevance must be mission driven, requiring focus and tradeoffs to achieve an acceptable balance. In addition, its definition of relevance can not be static, but rather requires ongoing evaluation and adjustment in light of a changing environment. In summary, relevance for an IS program is complex, multidimensional, and dynamic. These attributes are captured in the relevance model presented in the following section. 


\section{A RELEVANCE MODEL}

Figure 1 depicts a three dimensional model of relevance for an IS department. The primary dimension represents the stakeholders of the program, the secondary dimension the program's products, and the tertiary dimension that of the processes within the program.

These dimensions define a relevance space of discrete points which can be used to help quantify a program's relevance. Surrounding this relevance space are various aspects of the environment which influence the IS program and it stakeholders, products, and processes. The following sections describe this model in more detail.

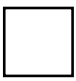

Figure 1. A Relevance Space

\section{Stakeholders}

A stakeholder of an IS program is an individual, group, or organization that has a vested interest in the program. Most stakeholders could be considered as customers of the program in the sense that they use the program's products (see following section). The most obvious example of a stakeholder is the program's students. Stakeholders are the value/relevance assessors, and hence the ones that must be satisfied with the program's products and processes. They are the ones who ask the "why" questions such as "Why do I have to take a certain class?" or "Why don't you use a certain tool or technique in your program?" Other examples of stakeholders include, but are not limited to Parents, Employers, the Educational System, theLlocal Community, and Society.

The employer stakeholder is equivalent to the "practitioners" discussed earlier in this paper. For the purpose of relevance assessment, this term is too general. It is important, therefore, that an IS program more fully understand the employers that hire most of its students. In particular, the size of the business (small, medium, large), their vertical market, and the IS/IT tools and techniques which they use are important factors in the determination of program relevance.

\section{Products}

Having a stakeholder assess the relevance of an IS program as a whole would be of little use in helping to improve relevance. For this, a more focused value context is required. The second dimension of the relevancy model shown in Figure 1 defines this value context as the outputs or products produced by the faculty within an IS program. Traditionally, there are at least three interrelated product lines with which most IS faculty are familiar. These are teaching, research, and service. As shown in Figure 2, the teaching product line is comprised of several products including the program's degrees, curriculum, courses, classroom teaching and associated materials, and the final overall product, the educated student.

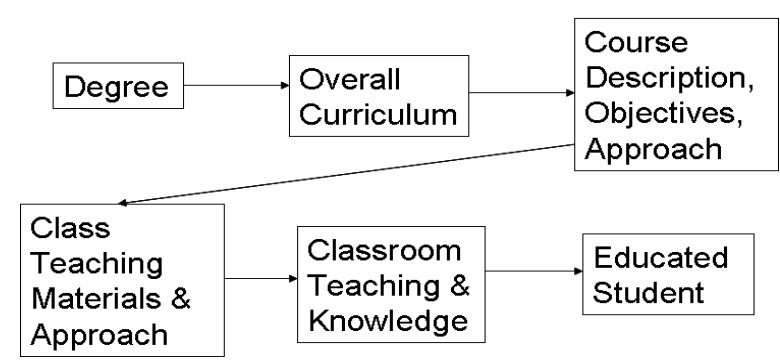

Figure 2: A Teaching Product Line

The arrows between the products indicate not only a required sequence, but also a dependency link. Keeping these dependencies in place and up-to-date is one of the biggest relevancy challenges that an IS department faces.

\section{Process}

The third dimension of the Relevance Model depicted in Figure 1 is that of process. A key principle of quality control is that product quality is in the process [11]. It seems clear that a similar principle applies to relevance. For example, a student may see a particular course as highly relevant to his future career. However, if the timing of the course offering or the teaching methods used in the classroom are not relevant to his needs and learning style, the relevance of the course and hence the overall IS program can be reduced. Similarly, the processes used to develop the other teaching products shown in Figure 2, along with the other product lines of research and service, must be considered in the relevance equation.

Regional and specialized accrediting bodies are the main auditors of process quality and obtaining their acceptance of an IS program can be a time consuming and expensive process itself. Not all 
stakeholders of the program, however, will view the relevance of such accreditation in the same way.

Finally, the IS department must also comply with the planning, organizational, and operational processes imposed upon it by the educational system within which it resides. Along with this come a host of constraints imposed by limited budgets, reduced faculty positions, and administrative decisions and mandates that limit the department's relevance efforts for other stakeholders.

\section{Environment}

The final aspect of the relevance model shown in Figure 1 is the changing environment which exerts a continuing influence on the relevance efforts of an IS department. Key aspects of this environment include but are not limited to the following: Competition, Best Practices, Research Results, Business Change, Technology Change, Organizational Change, Student Characteristics and Demographics, Student Preparation Levels, Government, Culture, and Global Issues.

Entire papers could be written about each of these factors, so it is imperative that the IS department continually monitor and assess the potential impact that these environment factors will have on the program's relevance. One example worth noting is the change in attitudes and characteristics of the current generation of students entering college. Sometimes called Generation "Y", or as Chester [5] puts it, Generation "Why," these students are not satisfied with the traditional approach to education. Since most of them have grown up in a world of relative ease with instant entertainment, instant access to information, and instant gratification of their needs, and since many are far superior to most faculty members in the use of the latest and greatest technology, they feel as if they have the right to question and challenge every aspect of their education, including which courses they take and how the courses should be taught. Achieving relevance for this new generation of studentstakeholders will be a significant challenge, not only for the IS department, but also for the educational system as a whole.

\section{A RELEVANCE RUBRIC}

Relevance measurement is a complex, multidimensional process that is affected by a changing environment. Past attempts at understanding relevance have focused on single relevance points and imputed their findings to the whole. Since it is impossible to be highly relevant to everyone in every area, to claim overall relevance, an IS department must first define what relevance means in its specific case. In this process, priorities must be established and tradeoffs made.

One way to accomplish this is to select three - five key stakeholders of the program by whom relevance will be assessed. Each stakeholder is given a percentage weight to prioritize its importance in the relevancy determination process. A set of relevance points from the model described earlier is then selected, perhaps by a focus group representing each stakeholder, or by the department, and weights attached to each point forming a relevance rubric. The next step is to determine a relevance success scale beyond a simple yes or no. For example, a Likert scale such as: 1="Not Successful", 2="Slightly Successful", 3="Successful", 4="Very Successful" and 5="Extremely Successful" might be used. An overall target goal is then set for the department.

To see if the program is meeting its relevance goals, a system for collecting data about the success of each relevancy point is established for each stakeholder type. As the relevancy exercise is carried out, feedback from the process is analyzed and relevance success scores are computed and compared to the program's goals. The following section contains a case example of this approach.

\section{A CASE EXAMPLE OF RELEVANCE}

State University (SU) is a mid-sized comprehensive regional university serving the state and its surrounding areas by offering graduate, baccalaureate, associate, and technical programs. SU provides individualized attention to its students with a focus on discovery-based learning in an intellectually stimulating environment. The SU Information Systems Department, residing in the College of Technology, offers a bachelor's degree in Information Systems designed in accordance with national curriculum guidelines. The program is regionally accredited but currently has no specialized accreditation. The mission of the department is "to prepare job-ready enterprise IS professionals for a global economy." The department has decided that, based on its mission and the goals of the university, its key stakeholders and percentage weights are: Regional Industry (40\%), Students (35\%), and the College Administration (25\%).

The IS department has an Advisory Committee made up of representatives from regional industries that hire its graduates. Articles from the literature such as 
[3] and [8] have been given to the committee and previous discussions with this group have led to the following relevance points and weights: Curriculum (40\%), Tools and Techniques being taught (30\%), Internships (15\%), Accreditation (10\%), and Faculty Research (5\%).

The student government at SU has elected an outstanding IS student to attend departmental meetings to represent the IS students. This leader has convened a group of students to discuss the program's relevance from their perspective. This group has identified the following relevance points and weights: Flexibility of Curriculum (30\%), Course Offering Schedule (30\%), Teaching Methods (20\%), and Facilities to Support Learning (20\%).

The College of Technology at SU has a Dean, two Associate Deans, an Assistant Dean, and several administrative assistants. These individuals are extremely busy, and it is difficult to get them together to focus on a single department's business. To help alleviate this problem, the Dean has scheduled quarterly lunch meetings with the various departments. Based on previous presentations by the deans and a more focused discussion at the last IS Department luncheon, the following relevance points and weights were identified: Student Learning and Teaching Excellence (40\%), Effective Use of Resources (30\%), Support for Regional Economic Development (20\%), and ABET Accreditation (10\%) After the relevance points and percentage weights were established for their three key stakeholders, the IS department set its relevance success goal at $80 \%$. It then began the process of collecting data to evaluate and improve its relevance rating.

At the next Advisory Committee meeting, members reviewed the IS curriculum and program and provided average success ratings (following the Likert scale discussed in the previous section) as follows: Curriculum $=3.2$, Tools and Techniques $=$ 4.1, Internships $=4.5$, Accreditation $=2.5$, and Faculty Research $=4.1$. Curriculum improvements were also suggested.

To gather data on student relevance ratings, a randomized student survey collected the following data: Flexibility of Curriculum $=2.4$, Course Offering Schedule $=2.9$, Teaching Methods $=4.2$, and Facilities to Support Learning $=3.1$. Student comments indicated the need for more elective courses, more evening offerings, and classrooms that were more laptop friendly.
Finally, relevance data collected from the college administration showed the following: Student Learning and Teaching Excellence $=4.5$, Effective Use of Resources $=3.9$, Support for Regional Economic Development $=1.5$, and ABET Accreditation $=2.2$.

Table 1 below summarizes the overall relevance evaluation. While the IS department did not meet its goal of $80 \%$ relevance $(3.4 / 5.0=68 \%)$, it did collect significant feedback which can be used to help improve its overall relevance rating. Because relevance is a moving target, the department will need to regularly verify its key stakeholders and associated relevance points and continue to collect corresponding relevance data.

Table 1. Relevance Report Card

\begin{tabular}{|c|c|c|c|c|c|}
\hline Relevance Points & $\begin{array}{c}\text { Relevance } \\
\text { Weight }\end{array}$ & $\begin{array}{l}\text { Success } \\
\text { Score }\end{array}$ & $\begin{array}{c}\text { Weighted } \\
\text { Success } \\
\text { Score }\end{array}$ & $\begin{array}{l}\text { Stakeholder } \\
\text { Weight }\end{array}$ & $\begin{array}{c}\text { Weighted } \\
\text { Relevance } \\
\text { Score }\end{array}$ \\
\hline \multicolumn{6}{|l|}{ Regional Industry } \\
\hline Curriculum & $40 \%$ & 3.2 & 1.28 & & \\
\hline Tools and Techniques & $30 \%$ & 4.1 & 1.23 & & \\
\hline Internships & $15 \%$ & 4.5 & 0.68 & & \\
\hline Accreditation & $10 \%$ & 2.5 & 0.25 & & \\
\hline Faculty Research & $5 \%$ & 4.1 & 0.21 & & \\
\hline Total & $100 \%$ & & 3.64 & $40.00 \%$ & 1.46 \\
\hline \multicolumn{6}{|l|}{ Students } \\
\hline Flexible Curriculum & $30 \%$ & 2.4 & 0.72 & & \\
\hline Class Scheduling & $30 \%$ & 2.9 & 0.87 & & \\
\hline Teaching Methods & $20 \%$ & 4.2 & 0.84 & & \\
\hline Facilities for Learning & $20 \%$ & 3.1 & 0.62 & & \\
\hline Total & $100 \%$ & & 3.05 & $35.00 \%$ & 1.07 \\
\hline \multicolumn{6}{|l|}{ Educational System } \\
\hline Teaching \& Learning & $40 \%$ & 4.5 & 1.80 & & \\
\hline Use of Resources & $30 \%$ & 3.9 & 1.17 & & \\
\hline Economic Development & $20 \%$ & 1.5 & 0.30 & & \\
\hline ABET Accreditation & $10 \%$ & 2.2 & 0.22 & & \\
\hline Total & $100 \%$ & & 3.49 & $25.00 \%$ & 0.87 \\
\hline Overall & & & & $100.00 \%$ & 3.40 \\
\hline
\end{tabular}

\section{CONCLUSION}

Many authors have made the claim that IS education has not kept up with a changing environment and thus has lost relevance. This paper has explored the meaning and measure of relevance for an academic IS program by presenting a relevance model and rubric. The work points out that an IS department must not only "do things right," but that it must first "do the right things" as determined by the program's stakeholders. Only by identifying key relevance points for its main stakeholders and by evaluating the degree to which the program is satisfying these criteria can relevance be determined.

\section{REFERENCES}


1. AACSB International (2006). http://www.aacsb.edu/, Referenced March 1

2. ABET Inc.(2006). http://www.abet.org/, Referenced March 1

3. Andriole, S. (2006). Business technology education in the early $21^{\text {st }}$ Century: The ongoing quest for relevance, Journal of Information Technology Education, 5(1), 1-12.

4. Benbast, I. \& Zmund, R.(1999). Empirical research in information systems: The practice of relevance, MIS Quarterly, 23(1), 3-16.

5. Chester, E. (2005). Getting Them to Give a Damn, Chicago, IL: Dearborn Trade Publishing.

6. Drysdale,S. (1996). What Should We Teach? ACM Computing Surveys, December.

7. Friedman, T. (2005). The World Is Flat. New York, NY: Farrar, Straus and Giroux.

8. Hoffman, T. (2003). Job skills: Preparing Generation Z, Computerworld, 37(34), 41.

9. Lethbridge, T. (1998). The relevancy of software education: A survey and some recommendations. Annals of Software Engineering,. 6(1), 91-110.
10. Lomerson, W \& Pollacia, L. (2005). Declining CIS enrollment: An examination of pre-college factors, Proceedings of the $22^{\text {nd }}$ Annual Information Systems Education Conference, October.

11. Summers, D. (2005). Quality Management: Creating and Sustaining Organizational Effectiveness, Upper Saddle River, NJ: Pearson Education, Inc.

12. Trauth, E., Farrell, D., \& Lee, D. (1993). The IS Expectation Gap: Industry Expectations vs. Academic Preparation, MIS Quarterly, 7(3), 293-307.

13. Westfall, R. (1999). An IS research relevance manifesto, Communications of the AIS, 2, (14), September. Available online at http://www.csupomona.edu/ rdwestfall/ais/relev ancymanifesto.html\#1\%20With. 